\title{
Revitalizing the Card Catalog
}

$\mathrm{C}$

ARD CATALOGS are growing in size and complexity at such an alarming rate that programs of catalog maintenance are becoming increasingly important to librarians. If the number of published papers on the subject is indicative of the extent of such projects, it appears that libraries are building catalogs but not repairing or reconditioning them. In 1953 Osborn and Haskins stressed the need of catalog maintenance. ${ }^{1}$ The Library of Congress has a plan of editing and refiling its catalog which is expected to take over eleven years and cost about $\$ 750,000 .^{2}$ For reasons of efficiency and economy, staffs of large and small libraries need to begin to plan now for revitalizing their card catalogs.

Such a project of card catalog revision was begun at Luther College Library, Decorah, Iowa, in the fall of 1953, because there was a feeling that the catalog was not serving as well as it could and should in aiding the college students, librarians, and other faculty members in locating library materials. The plan was initiated after discussion among all professional library staff members of the necessity for refiling the catalog because of inconsistencies in filing arrangements in various parts of the catalog, filing rules which seemed too complex for undergraduate students, and miscellaneous inadequacies.

1 Andrew D. Osborn and Susan M. Haskins, "Cata$\log$ Maintenance, Library Trends, II (1953), 279-89. 2 "Revised Proposal for Editing the Main and Offcial Catalogs." Memorandum, Dec. 29, 1952, from C. Sumner Spalding, Chief of the Catalog Maintenance of the Processing Department.

Miss Peterson is head of the catalog department, and Mr. Hovde is librarian, Luther College.
Concrete planning began with a series of staff discussions of the A.L.A. Rules for Filing Catalog Cards and a notation of which rules were to be followed. The original plan was simply to revise the filing, but it soon became apparent to the staff that it would be desirable and, on the whole, more economical to do as complete a revision as was possible in the process of checking through the catalog card by card. The entire plan was not completely formulated before the project began because some of the needs were not apparent until one of the librarians reached a section of the catalog in which the problem existed. Frequent short conferences were held during the process of refiling the first few trays to decide the ways in which those specific problems should be handled.

The revision project was carried out by the professional library staff, consisting of the head librarian, reference librarian, and catalog librarian, over a period of about one and one-half years. Each librarian tried to spend an hour each week-day morning on the project, but during especially busy times of the school year it was not possible to work regularly. The 271 catalog trays containing about 270,000 cards were divided numerically into sections and each librarian was given a specific area in which to work.

The following were the details of the revision project:

1. Cards were arranged in a word-forword alphabetical order wherever possible. Whenever the bulk of cards in a section, such as Bible, Luther, Shakespeare, warranted some other arrangement, cards explaining the filing order 
were placed at the beginning of the section and guide cards inserted to help clarify the deviation. Words with variant spellings were interfiled and cross references made from the form not used whenever that had not already been done.

2. Main entries for various editions were refiled in inverse chronological order.

3. Temporary cards which had been in the catalog for many years were pulled. The reviser then checked to see if permanent cards had been filed without removing the temporary ones. Later an evaluation of the remaining materials cataloged temporarily was made and withdrawal or permanent cataloging was carried out.

4. Cards which were worn out, dirty, illegible or handwritten were pulled. These cards, or sets of cards, were edited by the cataloger and retyped by the typist. Cards with typographical errors were pulled and given to the typist for correction. Old cards with Dewey Decimal Classification numbers which had not been removed when the collection was reclassified according to the Library of Congress system were withdrawn. Series cards for some insignificant series whose importance could not be fully appraised when first used and see also references which had been made for subjects not used in the catalog were also withdrawn.

5. Inconsistencies in forms of entry for the same person or body and in forms of subject headings were noted and corrected when they were so filed as to be obvious to the reviser. Obsolete subject headings were removed and referred to the cataloger who made the necessary changes to up-to-date terminology as given in the Library of Congress subject heading list.

6. Subject headings and references used in the card catalog (except form divisions or subdivisions that may be used with different classes of subject headings) were listed on sheets of paper. These lists were to serve as the basis for an accurate and more complete subject authority record. Because all the librarians worked during the early morning hours when the catalog area was not crowded and when they could readily confer on problems, it was not practical to check the subject authority book during the revision process. Perhaps it might have been preferable to purchase added copies of the subject heading book for checking along with the revision.

7. Inverted title cards were withdrawn. The cataloger later reviewed them, cancelling some, changing some to partial non-inverted titles, and assigning to others subject headings which had not been in use when the book was originally cataloged. A few were returned to the catalog as inverted titles. Since the cata$\log$ is in a dictionary arrangement, title cards were removed for books with identical, or almost identical, spellings of subject headings and titles.

8. Any other catalog cards which seemed to have inconsistencies, errors, or questions were pulled and referred to the catalog librarian for study.

9. Corrections and additions needed in guide cards were noted and new angle guide cards with printed headings were inserted.

10. Lastly, the cataloger shifted the catalog cards to eliminate uneven distribution in the trays and had new labels made for them.

The difficulties of the catalog revision resulted chiefly from the mildly chaotic state of the catalog during the year and a half that the project was being done. However, it was found that few students commented or complained about the existing inconsistencies. Perhaps the chief difficulty was in filing and revising the filing of new cards. The attempt was made to file new cards by the new method whenever that could be done 
without isolating them from those for related materials already in the catalog.

In the opinion of the library staff, the benefits of the project far outweigh the difficulties involved and the time and effort spent. The catalog is now more accurate and complete because some errors in cataloging, typing, and filing have been eliminated. Statistics of the number of cards withdrawn from the catalog were not kept, but the removal of cards for see also references, inverted titles, and unnecessary series did result in a slight reduction of the size of the catalog. The librarians believe that they learned much about the book collection represented by the cards in their particular section of the catalog. The reference librarian also says that she learned a great deal about cataloging and can better interpret the book collection from the catalog. She reports that she actually misses her daily stint of card catalog revision!

\section{Southern University Libraries in the Twentieth Century}

(Continued from page 389)

indispensable part of any program of interlibrary cooperation.

Finally, the university libraries of the South have felt the need for some broadly based organization in the region to serve (1) as a clearing house and discussion ground for cooperative projects and (2) to give direction, guidance, and support to those that are deemed sufficiently important. The genesis and spirit of this idea is to be found in SIRF, the Southeastern Interlibrary Research Facility. SIRF as now defined, however, is limited to library cooperation between university libraries in Georgia and Florida; if the regional aims of the Southern Regional Education Board are to be carried out, SIRF should become a genuinely regional library cooperative organization. This will come about, it seems to me, inevitably, but the immediate roadblock to expanding SIRF is the cost to the participating libraries of maintaining a strong central organization to give thrust and momentum to the ideas for cooperative action generated by the librarians of the region. If the Southern Regional Education Board could see its way clear to maintaining and financing a library department, particularly in the next few years when southern university libraries are straining every dollar to strengthen their collections and services, it would greatly speed up the machinery of interlibrary cooperation and enable us to serve scholarship better in the Southeast. I am aware that the proposal for establishing a library department of the Southern Regional Education Board is one which is asking the board to undertake an additional financial responsibility of some magnitude. On the other hand, each library will be contributing substantially from its own funds and staff time in assisting the department to carry out specific cooperative bibliographic projects. The extension I suggest would provide additional services beyond what could be provided by a library association staffed with purely voluntary assistance. It is the kind of extension which I feel sure the Southern Regional Education Board, of which our principal speaker is an important member, would not refuse if it were satisfied that it was for the general welfare of education in the South; moreover, this would enable it to extend some portion of the benefits of their public funds to the great multitude of scholars in the South who do not have the neighboring backstop of great repositories such as exist in the Harvard and Yale University libraries. 